\title{
OPTIMIZING BREAKWATER DESIGN CONSIDERING THE SYSTEM OF FAILURE MODES
}

\author{
Campos, A. ${ }^{1}$, Castillo, C. ${ }^{1}$ and Molina, R. ${ }^{2}$ \\ Optimization techniques have been applied to breakwater design in order to automate the design process (Castillo et \\ al. 2004, 2006). Since safety of structures is the fundamental criterion for design, a complete knowledge of the \\ potential failure modes, as well as the possible interaction between them, is essential to provide a consistent design. \\ Failure modes are correlated in two ways: through common parameters like $\mathrm{H}_{\mathrm{S}}$ or by physical interaction. The latter \\ has not yet been precisely identified nor quantified. The aim of the present paper is to advance on the analysis of both \\ types of correlations and to check how the combination of failure modes modifies the failure probability of the whole \\ structure either increasing or decreasing it. An application to a special type of composite breakwater is proposed: the \\ fuse parapet case, where part of the parapet fails under certain circumstances in order to ensure the whole stability of \\ the caisson, despite increasing overtopping events.
}

Keywords: Cost optimization, Failure probability, Failure modes, Reliability-based design, Fuse-parapet.

\section{INTRODUCTION}

Coastal engineering design of structural elements is a complicated and highly iterative process that usually requires an extensive experience. Iterations consist of a trial-and-error selection of the design variables or parameters, together with a check of the safety and functionality constraints, until reasonable structures, in terms of cost and safety, are obtained.

Due to the mentioned iterative process, optimization procedures are a good solution to automate the design. The values of the design variables are given by the optimization process whereas the task of the engineer is to determine the constraints and the objective function to be optimized (costs fundamentally).

Safety, the fundamental criterion for design, is verified in terms of failure modes: initially, the engineer must identify every failure mode of the structure and, after that, the safety constraints to be satisfied are determined. In order to ensure the fulfillment of the safety constraints, different approaches can be used:

1. The classical safety factor approach, which has the advantage of being easily interpreted in terms of their physical or engineering meaning, but does not give clear information about the reliability of the structure.

2. The probability based approach, which gives a clue about how far is a certain design/structure from the failure but, on the other hand, is very sensitive to statistical hypotheses, especially tail assumptions (Galambos 1987, Castillo 1988). This approach is being developed nowadays and has been recently included in some Manuals (e.g. Spanish ROM, European PROVERBS).

3. The probability-safety factor design approach proposed by Castillo et al. (2004), which combines safety factors and failure probability constraints and permits the procurement of a more reliable design: it guarantees given safety factors and failure probability bounds.

In order to obtain a reliable design, the engineer must firstly identify every failure mode involved with the structure. Traditionally, they are considered as independent. However, the combination or relations among them could be especially relevant when applying probability or probability-safety factor design methods.

This problem can be easily interpreted using diagrams known as fault trees. In order to illustrate this concept, let us consider just two failure modes $\left(\mathrm{M}_{1}, \mathrm{M}_{2}\right)$. When considering the safety of the structure, the following cases can occur:

- No failure occurs

- Only Failure $\mathrm{M}_{1}$ occurs

- Failure $\mathrm{M}_{1}$ induces failure $\mathrm{M}_{2}$

- Only Failure $\mathrm{M}_{2}$ occurs

- Failure $\mathrm{M}_{2}$ induces failure $\mathrm{M}_{1}$

- Simultaneous failure of $\mathrm{M}_{1}$ and $\mathrm{M}_{2}$ occurs

\footnotetext{
${ }_{1}^{1}$ University of Castilla-La Mancha. Edificio Politécnico. Avda. Camilo José Cela, s/n. 13071, Ciudad Real (Spain).

${ }^{2}$ Ports Laboratory of the Polytechnic University of Madrid. Calle del Profesor Aranguren, 1. 28040, Madrid (Spain).
} 
Figure 1, based on Gómez et al. (2009), represents the fault tree for this case. Notice that $\mathrm{M}_{0}$ represents the non-failure situation, $\mathrm{X}$ indicates that a stable situation has been reached (no more failure modes are developed) and $\mathrm{N}_{0}, \mathrm{~N}_{1, \mathrm{X}}, \mathrm{N}_{1,2, \mathrm{X}}, \mathrm{N}_{2, \mathrm{X}}, \mathrm{N}_{2,1, \mathrm{X}}, \mathrm{N}_{12}$ are the number of registered events for each combination in the fault tree.

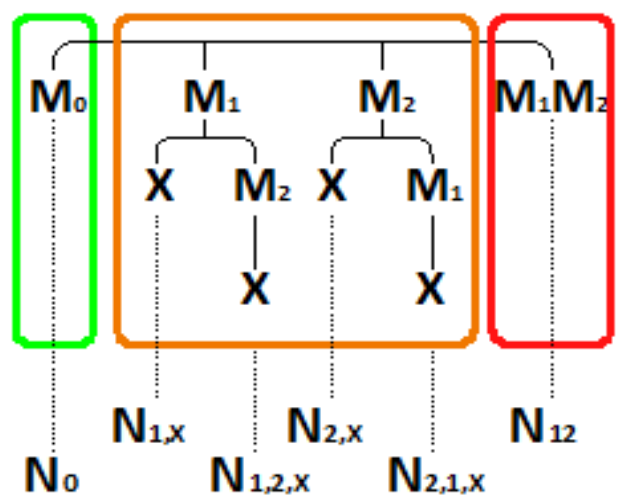

Figure 1. Fault tree for a system of two failure modes.

Failure modes are correlated in two ways:

- Through common parameters (like $\mathrm{H}_{\mathrm{S}}$ ), which is straightforward.

- By physical interaction, which represents more accurately the real behavior of the structure. For example, berm erosion or toe erosion can induce an armor slip, in vertical breakwaters the caisson tilting could affect the sliding distance, or there is a clear correlation between rear slope stability and mean overtopping discharge in rubble mound breakwaters. However, deeper research is needed to obtain reliable equations physically relating different failure modes, because nowadays there is not enough information available.

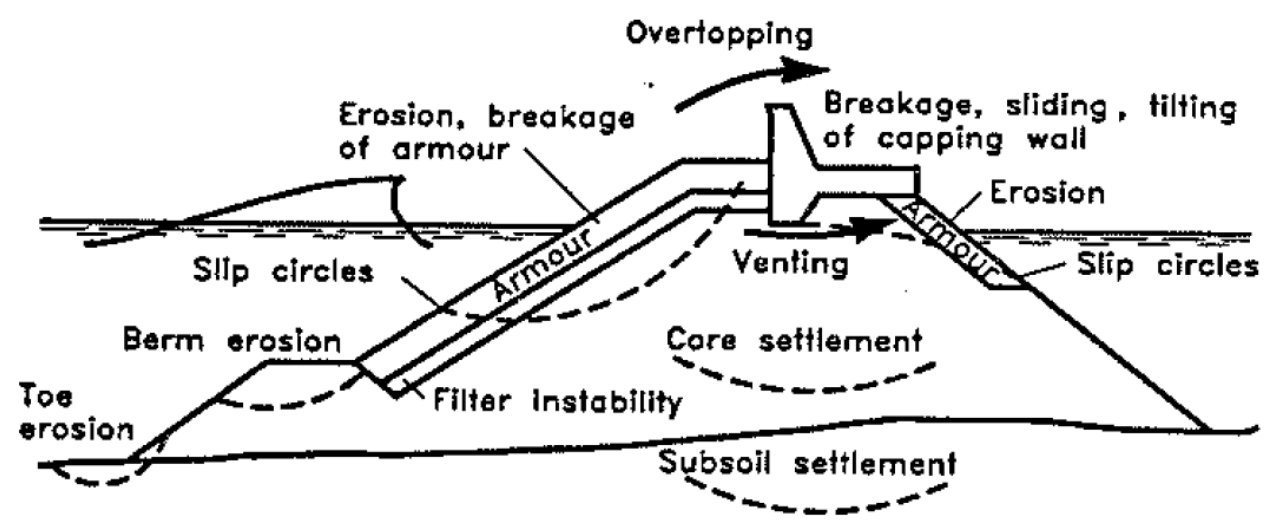

Figure 2. Failure modes for a rubble mound breakwater (Burcharth 1997)

The constraints regarding failure probabilities can be related to each failure mode or to combinations of them. If, for the previous example, the safety of the structure against $\mathbf{M}_{1}$ is to be determined, all cases involving $\mathrm{M}_{1}$ should be considered which, using a probabilistic approach, means that the following probabilities must be evaluated:

- The probability of $\mathrm{M}_{1}$ failing first $\left(P_{f}\left[M_{1}\right]\right)$.

- The probability of the simultaneous failure of $\mathrm{M}_{1}$ and $\mathrm{M}_{2}\left(P_{f}\left[M_{12}\right]\right)$ : combination of failure modes through common parameters.

- The failure probability of $\mathrm{M}_{1}$ when $\mathrm{M}_{2}$ fails first $\left(P_{f}\left[M_{1} \mid M_{2}\right]\right.$, which is known as conditional probability) multiplied by the probability of $\mathrm{M}_{2}$ failing first $\left(P_{f}\left[M_{2}\right]\right)$ : combination of failure modes through physical interaction.

In this sense, the total failure probability associated with $\mathrm{M}_{1}\left(P_{T O T A L f}\left[M_{1}\right]\right)$ is summed up in Equation (1): 


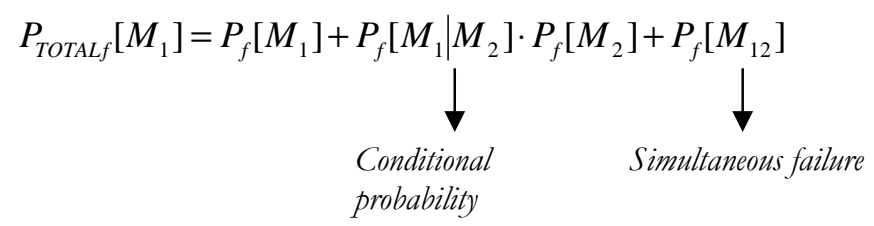

And, if the constraint regarding failure probability refers only to M1, it can be stated as $P_{\text {TOTALf }}\left[M_{1}\right] \leq \mathrm{P}_{\text {LIM }}$.

In a breakwater many failure modes can occur, as it is shown in Figure 2. The system of failure modes involves not only the single failure mechanism, but also every possible combination between them. Because of its complexity, fault trees are particularly useful to clarify the relations between failure modes. Nowadays it's possible to calculate the probabilities associated with the upper part of the tree in Figure 1, but there's still not enough information to determine conditional probabilities related to the lower part.

\section{THE FUSE PARAPET CASE}

Combination of failure modes modifies the failure probability of the whole structure. In the previous examples, it has been exposed how the system of failure modes can increase the failure probability of the whole structure. But it is also possible to re-interpret the problem with a new vision: how a combination of failure modes can reduce the failure probability of the structure despite the fact that some modes increase their probability.

The idea is to induce the occurrence of failure modes which would cause minor damage to the structure (and, therefore, increase their probability) in order to avoid the occurrence of other failure modes which would cause major damage to the structure.

To illustrate this, a composite breakwater design is proposed in which the parapet has a fuse part, that is, that fails on purpose under critical circumstances (see Figure 3). Consequently overtopping increases, but sliding and overturning probabilities decrease, as the surface exposed to wave's pressures is reduced.

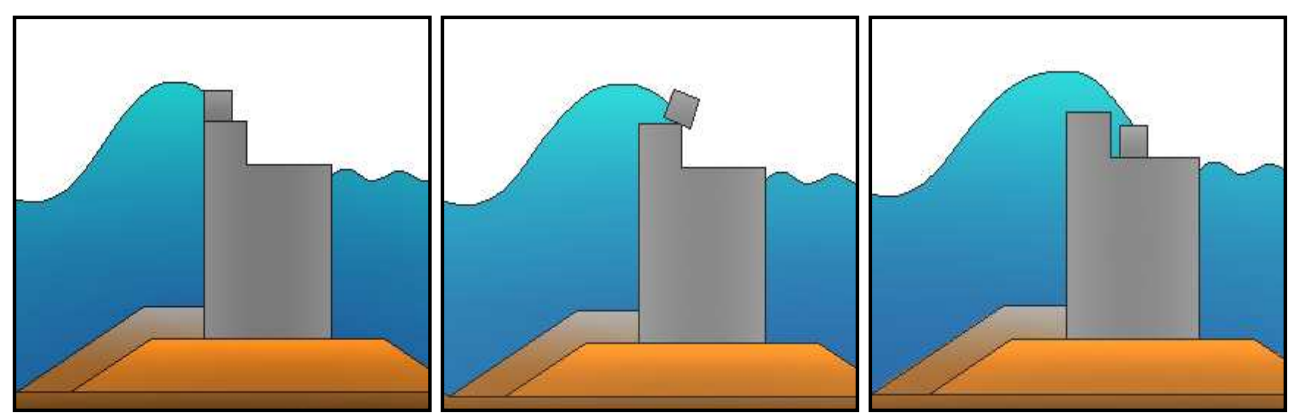

Figure 3. Scheme of the fuse parapet case

Deep water caissons usually have overdimensioned parapet in order to ensure the operationality of the port. Consequently, wide caissons are needed to withstand the induced high pressures and therefore the construction cost is significant. An alternative way of facing that situation is precisely assuming certain risks in the design, which is the basis of the fuse parapet case.

The main initial consideration is the design criteria of the fuse parapet, considering both the geometry of the parapet and the definition of those parts designed to fail under certain circumstances. For the sake of simplicity, a rectangular shape of the parapet is assumed. Regarding the fuse design, different initial schemes have been considered (see Figure 4):

- Scheme 1. The whole parapet is designed to fail under certain circumstances.

- Scheme 2. The parapet is divided in two fuse parts: the upper part may fail when it is exposed to a certain pressure diagram, whereas both of them may fail considering a more severe pressure diagram. Notice that the upper part will always fail first.

- Scheme 3. There is a fixed parapet at the bottom and an upper part designed to fail under certain circumstances. 


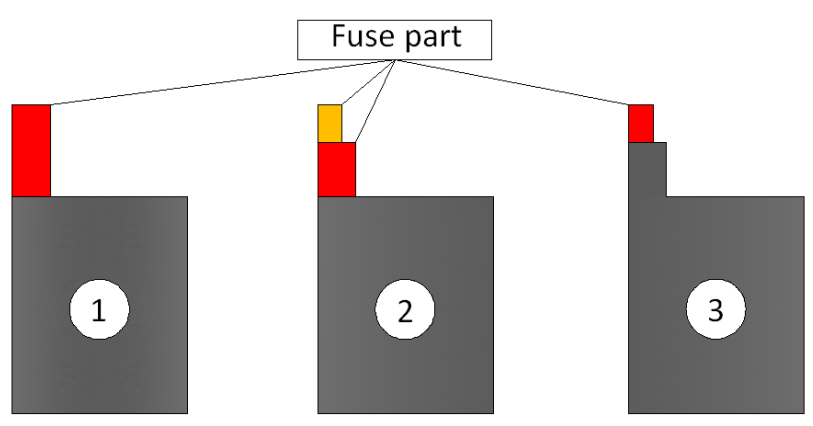

Figure 4. Design schemes of the fuse part

Assuming that fuse parts stay on the top of the structure after failing, schemes 1 and 2 present a physical limitation: fuse parapets will keep on transferring unstable stresses to the structure due to the fact that they still oppose an effective surface to the dynamic pressures of the marine climate. The fixed part in Scheme 3 also presents that limitation. However, as it is fixed, it also ensures the stable effect of its self weight. Considering that overturning is the potential failure of the fuse parapet, the fixed parapet height should be greater than the fuse parapet width, in order to avoid pressure diagrams above the fixed parapet.

Regarding these considerations, the fuse parapet case is defined as a composite breakwater whose superstructure follows the design of scheme 3. Notice that several assumptions have to be taken, waiting for a dynamic study of the superstructure to confirm or modify them. One of these assumptions is shown in Figure 5 where it is shown that, when failing, the fuse part of the parapet remains on top of the caisson and it is sticked to the fixed part after overturning.

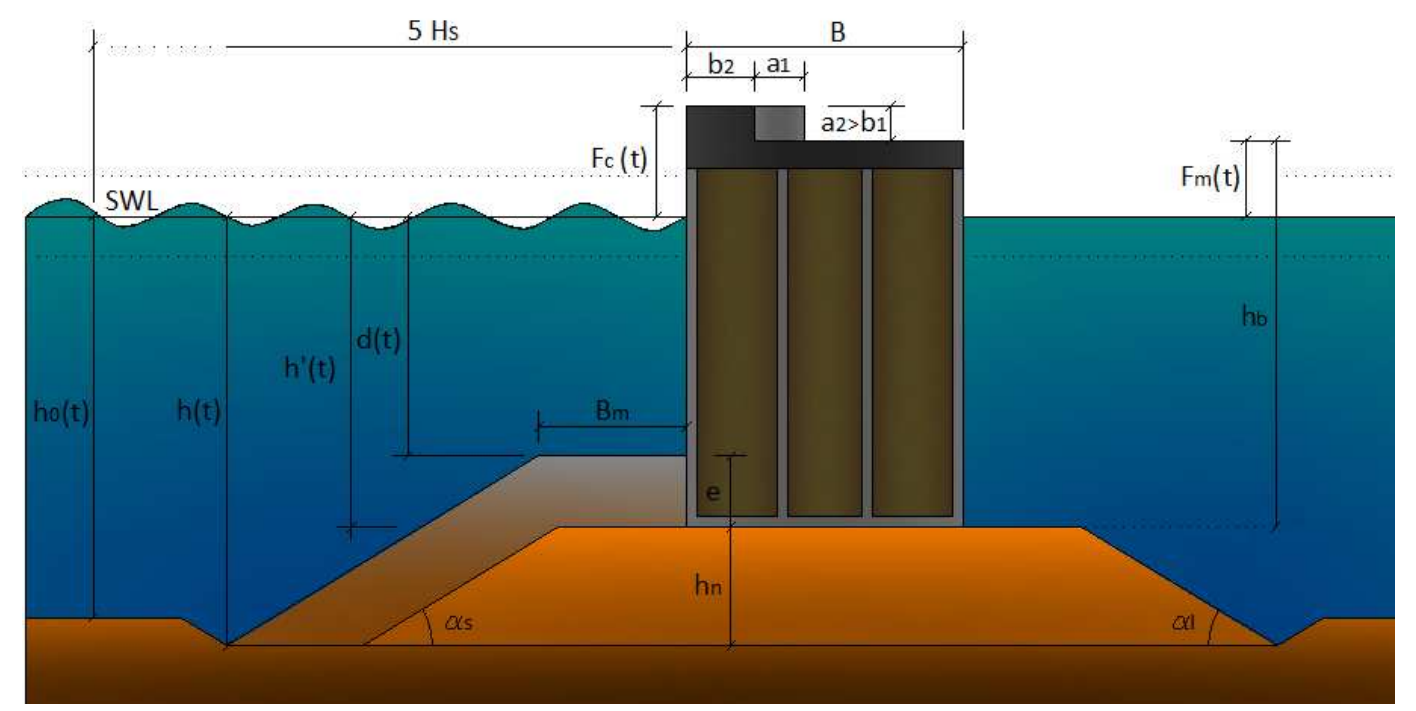

Figure 5. Location of fuse part of parapet after failure

\section{CASE STUDIES}

Two different cases are distinguished and an optimization study has been carried out for each of them. The optimization design variables involve just the ones related to the superstructure and the caisson width, whereas the caisson height, berm and foundation are considered as data.

\subsection{Case 1: Fuse parapet}

In this case, only the lower part of the parapet is fixed and two situations are possible: when the fuse parapet is in place and when it has failed. The geometrical layout between these situations, especially relevant when verifying the safety constrains, is slightly different: the only variation is the position of the fuse parapet which, as it was said before, remains on the top of the structure (see Figure 5). 
Optimized design variables are pointed out in Figure 6. These are:

- $\mathrm{B}=$ caisson width.

- $\mathrm{b}_{1}=$ fuse parapet width.

- $\mathrm{b}_{2}=$ fixed parapet width.

- $\mathrm{a}_{1}=$ fuse parapet height.

- $\mathrm{a}_{2}=$ fixed parapet height.

- $\mathrm{A}=$ critical value related to $\eta *$ for fuse parapet failure ( $\eta *$ is a Goda's formulation parameter, see Section 5).

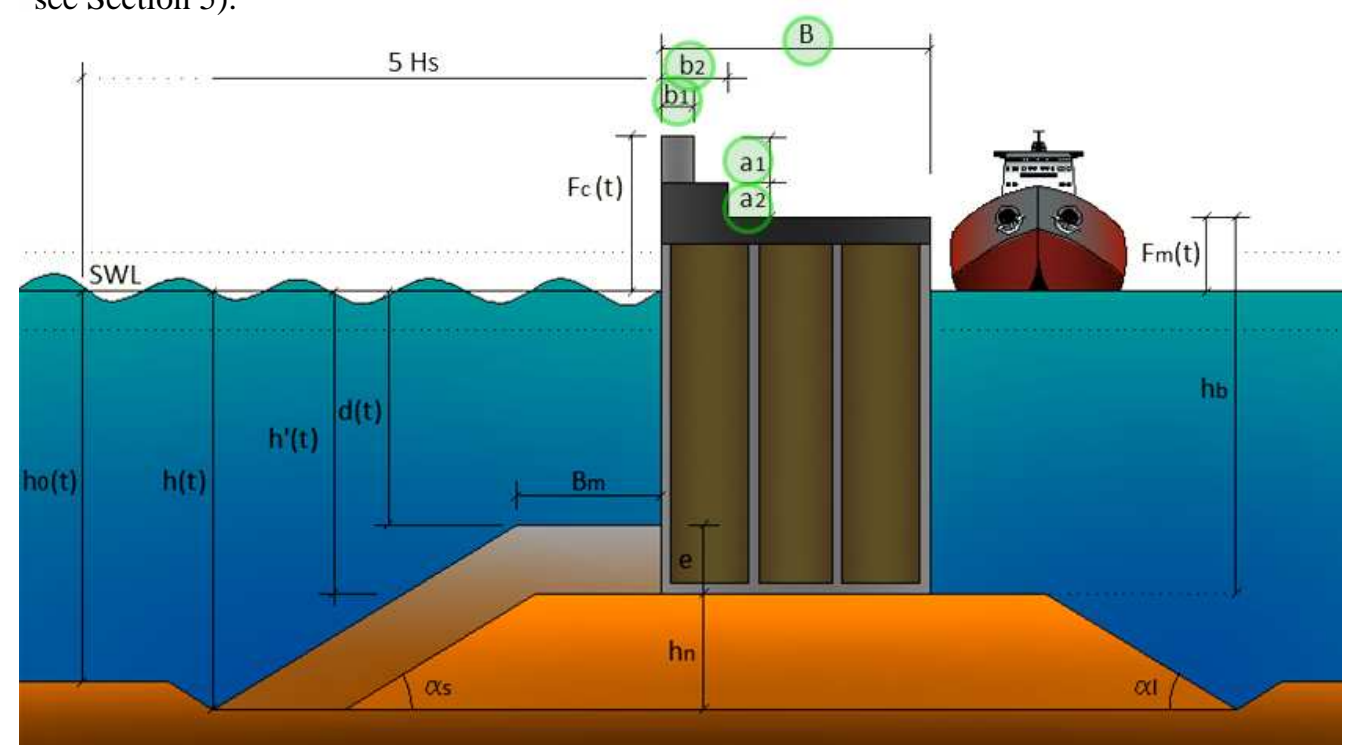

Figure 6. Optimized design variables

Non-optimized design variables are those ones given as data. They are divided into fixed and variable. Non-optimized fixed design variables are related to the geometry of the foundation and the berm and height of the caisson. The rest of non-optimized variables are highlighted in Figure 7 and their values related to the SWL are summed up in Table 1. These variables are:

- $\mathrm{h}(\mathrm{t})=\mathrm{h}+$ astronomical tide + storm surge: water depth in front of the breakwater

- $\mathrm{h}_{0}(\mathrm{t})=\mathrm{h}_{0}+$ astronomical tide + storm surge: depth at a distance of $5 \mathrm{H}_{\mathrm{S}}$ seaward of the breakwater

- $\mathrm{d}(\mathrm{t})=\mathrm{d}+$ astronomical tide + storm surge: depth above the berm

- $\quad h^{\prime}(t)=h^{\prime}+$ astronomical tide + storm surge: depth above the foundation of the caisson

- $\mathrm{F}_{\mathrm{m}}(\mathrm{t})=\mathrm{F}_{\mathrm{m}}-$ (astronomical tide + storm surge): leeward freeboard

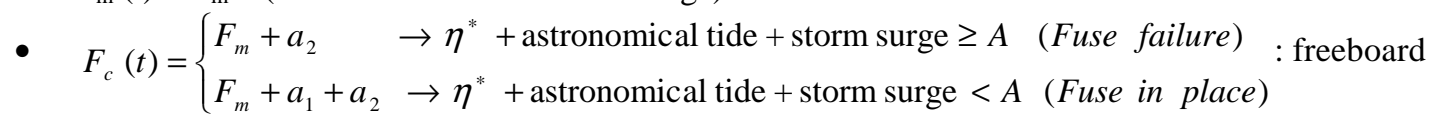

Equations associated with the value of $F_{c}$ are correlated with the limit state equation of the fuse parapet, detailed in Section 6.

\begin{tabular}{|l|l|l|l|l|l|l|l|}
\hline \multicolumn{7}{|c|}{ Table 1. Non-optimization fixed design variables } \\
\hline $\mathrm{h}$ & $34.88 \mathrm{~m}$ & $\mathrm{~h}_{\mathrm{n}}$ & $8 \mathrm{~m}$ & $\mathrm{~h}_{0}$ & $30 \mathrm{~m}$ & $\mathrm{\alpha}_{\mathrm{s}}$ & $\arctan (1 / 1.65)$ \\
\hline $\mathrm{h}^{\prime}$ & $26.88 \mathrm{~m}$ & $\mathrm{e}$ & $4.75 \mathrm{~m}$ & $\mathrm{~h}_{\mathrm{b}}$ & $32 \mathrm{~m}$ & $\mathrm{\alpha}_{\mathrm{l}}$ & $\arctan (1 / 1.65)$ \\
\hline $\mathrm{d}$ & $22.13 \mathrm{~m}$ & $\mathrm{~B}_{\mathrm{m}}$ & $10 \mathrm{~m}$ & $\mathrm{~F}_{\mathrm{m}}$ & $5.12 \mathrm{~m}$ & & \\
\cline { 1 - 3 }
\end{tabular}

\subsection{Case 2: Fixed parapet}

This case is used to compare the solution of Case 1 with the conventional design. Therefore, a double check has been carried out. On the one hand, the solution of Case 1 has been verified considering a fixed parapet; this situation is named Case 2.1. Predictably, it won't satisfy safety constraints, that is the reason why, on the other hand, the minimum caisson width has been calculated in order to fulfill safety constraints; this situation is named Case 2.2. Notice that in both cases the geometry of the superstructure is the one obtained in Case 1, but the whole parapet is considered as fixed. 




Figure 7. Non-optimized design variables

\section{AGENTS}

The agents considered are related to the marine climate: water level and waves. A statistical study of the astronomical tide, storm surge, maximum significant wave height of a storm, maximum wave height of the storm and period of the maximum wave height has been carried out in a generic point of the North of Spain, obtaining the following conclusions:

$$
\begin{gathered}
\text { Astronomical tide } \approx\left[0.5 \times N\left(1.946,0.591^{2}\right)+0.5 \times N\left(3.716,0.566^{2}\right)\right]_{0}^{5.5} \\
\text { Storm surge } \approx N\left(0.02414,0.11597^{2}\right) \\
H_{S, \text { max }} \mid \theta \approx G P D_{M}\left(\lambda_{S}(\theta), \delta_{S}(\theta), \kappa_{S}(\theta)\right) \\
H_{\max } \mid H_{S, \text { max }}, \theta \approx W_{M}\left(\alpha_{r}(\theta)+\beta_{r}(\theta) H_{S, \text { max }}+\lambda_{w}(\theta), \delta_{W}(\theta), \kappa_{W}(\theta)\right) \\
T_{z, \text { max }} \mid H_{\max }, H_{S, \text { max }}, \theta \approx N\left(a_{t}(\theta)+b_{t}(\theta) H_{S, \text { max }}+c_{t}(\theta) H_{\text {max }}, \sigma_{T_{z, \text { max }}}^{2}(\theta)\right)
\end{gathered}
$$

\section{ACTIONS}

Pressures acting on the wall are calculated using Takahashi formulation for impact waves and Goda formulation for breaking waves. Different schemes of $\eta^{*}$ are possible, taking into account the modification in the pressure diagram when fuse failure occurs (see Figure 8):

- Situation 1, when the pressure diagram is under the fuse parapet and, consequently, it is in place.

- Situation 2, when the pressure diagram reaches the fuse parapet. It is considered that the induced pressures are not sufficient to produce the fuse failure.

- Situation 3, when the pressure diagram is above the fuse parapet, but it is not severe enough to make it fail.

- Situation 4, when the pressure diagram is above the fuse parapet, which has failed. Notice that in this case effective pressures reach just the top of the fixed parapet.

Overtopping discharge, which may cause operationality problems and damage in the activities related to the breakwater, has been calculated applying Franco's formulation. Again, it has been distinguished between different situations (see Figure 8):

- Situation 1, when the fuse parapet is in place and, consequently, the freeboard is measured considering the whole parapet.

- Situation 2, when the fuse parapet has failed. In this case the freeboard is measured considering just the fixed parapet. 


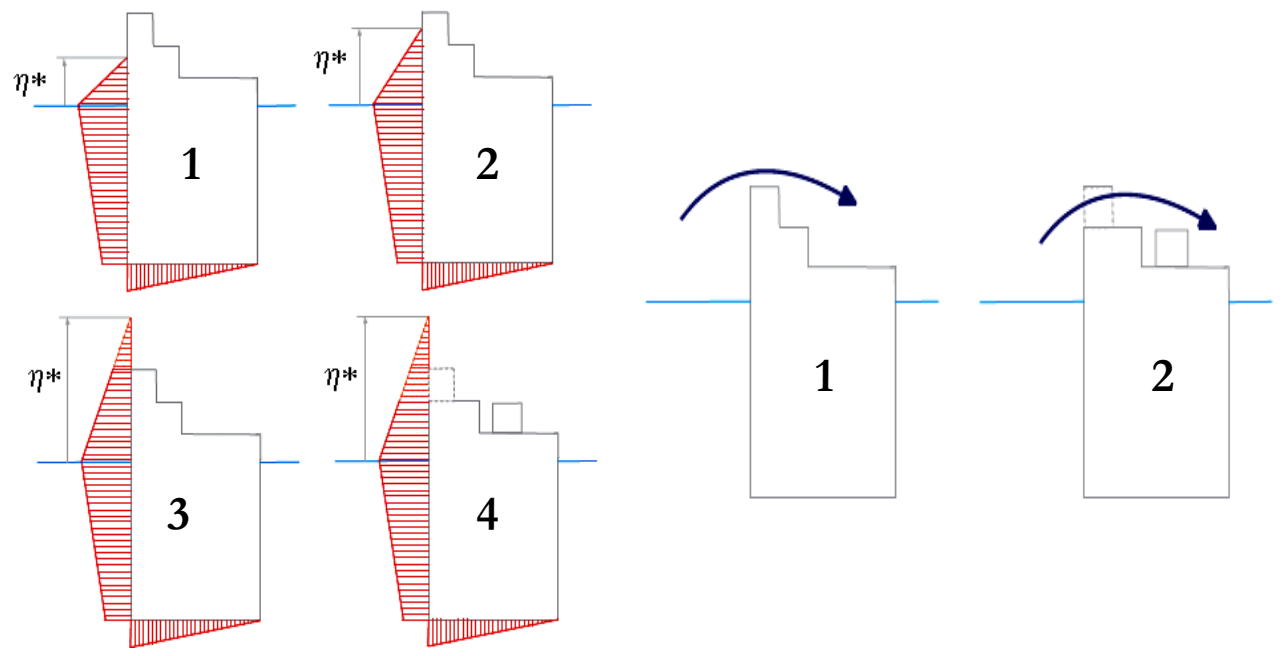

Figure 8. Possible pressure diagrams and freeboard layouts taken into account during the optimization process

\section{FAILURE MODES}

For simplicity, only four failure modes have been considered: three associated with Ultimate Limit States (fuse failure, overturning and sliding) and one related to Serviceability Limit State (overtopping).

- Fuse failure, based on an assumed overturning of the fuse parapet, as it was described in Section 2. The limit state equation is:

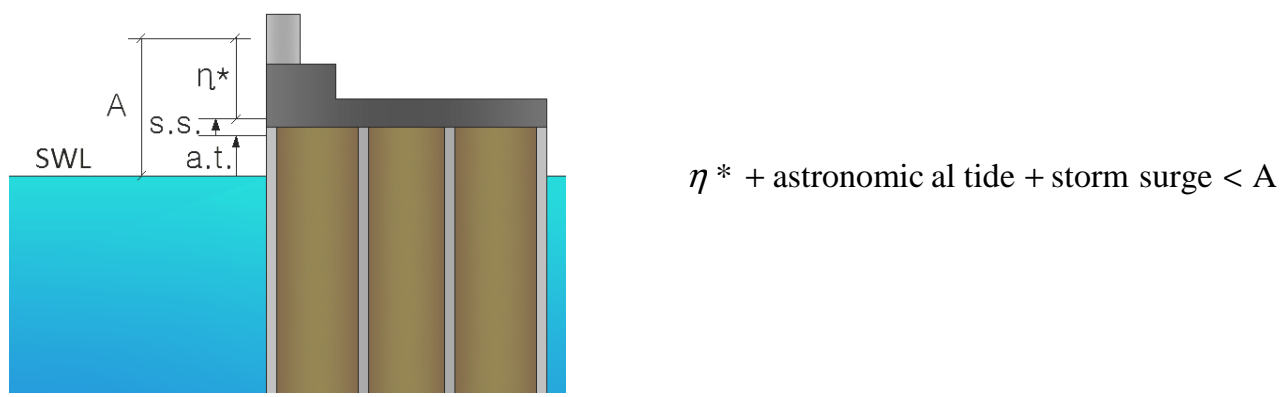

Figure 9. Design criteria of the fuse failure

where $\eta^{*}$ is a parameter of Goda's formulation and $A$ is an optimization variable (see Section 3.1). Notice that $\eta^{*}$ is referred to the water level of each storm, whereas $A$ is referred to SWL (see Figure 9). Equation 3 expresses that fuse failure is produced when the pressure diagram reaches a certain height $A$, determined in the optimization process.

- Sliding, which limit state equation is:

$$
\mu_{C}\left(W+W_{1}+W_{2}-F_{V}\right) \geq F_{H}
$$

where $\mu_{C}$ is the friction coefficient (0.6, assumed constant), $W$ is the caisson's weight, $W_{1}$ is the fuse parapet's weight, $W_{2}$ is the fixed parapet's weight, $F_{V}$ is the effective uplift's force and $F_{H}$ is the effective horizontal force.

- Overturning, which limit state equation is:

$$
W \cdot y+W_{1} \cdot y_{1}+W_{2} \cdot y_{2}-M_{V} \geq M_{H}
$$

where $W$ is the caisson's weight, $W_{1}$ is the fuse parapet's weight, $W_{2}$ is the fixed parapet's weight, $y$ is the caisson's lever arm, $y_{1}$ is the fuse parapet's lever arm (notice that this value differs when the fuse is in place and when it has failed), $y_{2}$ is the fixed parapet's lever arm, $M_{V}$ is the moment of the effective uplift's force and $M_{H}$ is the moment of the effective horizontal force. 
- Overtopping, which limit state equation is:

$$
\mathrm{q} \leq \mathrm{qLIM}
$$

where $\mathrm{q}_{\mathrm{LIM}}$ is determined using the EUROTOP guidelines: $0.01 \mathrm{~m}^{3} / \mathrm{s} / \mathrm{m}$ for potential damage to larger yachts.

\section{OPTIMIZATION PROCESS}

The optimization process proposed in the present paper involves the consideration of failure probabilities. Regarding the Spanish ROM 0.0-01, it is recommended to use Level II or Level III methods. In this particular case, a Level III method has been applied based on Monte Carlo techniques: initially the agent's values are simulated randomly, after that the actions generated are determined and finally the verification equations of the different failure modes are evaluated.

Optimization techniques have already been applied to breakwater design (see Castillo 2006, Mínguez 2006), but the physical correlation among failure modes was not taken into account. In the present paper the optimization involves the minimization of the initial cost, although further analysis of the fuse parapet case may include maintenance costs as well. The cost function to be minimized, considering only the caisson and parapets and assuming a constant cost per unit volume of $60.1 \$ / \mathrm{m}^{3}$, is:

$$
\text { Cost }=C_{\text {caisson }}+C_{\text {fixed parapet }}+C_{\text {fuse parapet }}=C_{\text {concrete }} \cdot V_{\text {concrete }} \approx 60.1 \cdot\left[\left(B h_{b}\right)+\left(b_{2} a_{2}\right)+\left(b_{1} a_{1}\right)\right]
$$

The reliability constraints applied for each failure mode (overtopping, sliding and overturning) are:

$$
\begin{aligned}
& P_{f, o} \leq 0.01 \\
& P_{f, s} \leq 0.001 \\
& P_{f, t} \leq 0.001
\end{aligned}
$$

There is no constraint for the fuse failure, although in a real design it should be according to the operationality constraints of the port. Notice that failure probability of overtopping can be greater than the associated with sliding and overturning, because it is a Serviceability Limit State (Proverbs 2005).

As it was exposed before, there is a physical correlation of the fuse failure with the rest of failure modes. Regarding the considerations about conditional probability of Section 1, failure probabilities are calculated as follows:

$$
\begin{aligned}
& P_{f, o}=P_{f, o 1} \cdot\left(1-P_{f, f}\right)+P_{f, o 2} \cdot P_{f, f} \\
& P_{f, s}=P_{f, s 1} \cdot\left(1-P_{f, f}\right)+P_{f, s 2} \cdot P_{f, f} \\
& P_{f, t}=P_{f, t 1} \cdot\left(1-P_{f, f}\right)+P_{f, t 2} \cdot P_{f, f}
\end{aligned}
$$

\begin{tabular}{|c|c|c|c|c|c|c|c|}
\hline \multicolumn{8}{|c|}{ Table 2. Results of the optimization of Case 1} \\
\hline \multicolumn{2}{|c|}{ Optimized values } & \multicolumn{2}{|c|}{ Failure involving fuse failure } & \multicolumn{2}{|c|}{ Failure with fuse in place } & \multicolumn{2}{|c|}{ Total probabilities } \\
\hline $\mathrm{B}$ & $18.2 \mathrm{~m}$ & $\mathrm{~F}+\mathrm{S}+\mathrm{T}+\mathrm{O}$ & 0.00054 & $\mathrm{~S}+\mathrm{T}+\mathrm{O}$ & 0 & $\mathrm{~F}$ & 0.00690 \\
\hline$b_{1}$ & $1.5 \mathrm{~m}$ & $\mathrm{~F}+\mathrm{S}+\mathrm{T}$ & 0 & $\mathrm{~S}+\mathrm{T}$ & 0 & $\mathrm{~S}$ & 0.00054 \\
\hline$b_{2}$ & $4.6 \mathrm{~m}$ & $\mathrm{~F}+\mathrm{S}+\mathrm{O}$ & 0 & $\mathrm{~S}+\mathrm{O}$ & 0 & $\mathrm{~T}$ & 0.00099 \\
\hline$a_{1}$ & $4.0 \mathrm{~m}$ & $\mathrm{~F}+\mathrm{T}+\mathrm{O}$ & 0.00045 & $\mathrm{~T}+\mathrm{O}$ & 0 & $\mathrm{O}$ & 0.01 \\
\hline$a_{2}$ & $1.5 \mathrm{~m}$ & $\mathrm{~F}+\mathrm{S}$ & 0 & $\mathrm{~S}$ & 0 & & \\
\hline Cost & $35777.5 \$ / \mathrm{m}$ & $\mathrm{F}+\mathrm{T}$ & 0 & $\mathrm{~T}$ & 0 & & \\
\hline \multirow[t]{2}{*}{ 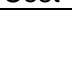 } & & $\mathrm{F}+\mathrm{O}$ & 0.00592 & $\mathrm{O}$ & 0.00329 & & \\
\hline & & $\mathrm{F}$ & 0 & No failure & 0.98980 & & \\
\hline
\end{tabular}

where subindex 1 means fuse in place, 2 is referred to the situation after fuse failure and $f, s, t, o$ are associated with fuse failure, sliding, overturning and overtopping respectively.

\section{RESULTS}

The results of the optimization process for cases 1, 2.1 and 2.2 are summarized in Table 2 and Table 3, whereas the optimized geometry of cases 1 and 2.2 is illustrated in Figure 10. 


\begin{tabular}{|c|c|c|c|c|c|c|c|c|c|}
\hline \multicolumn{4}{|c|}{ Case 2.1} & \multicolumn{6}{|c|}{ Case 2.2} \\
\hline \multicolumn{2}{|c|}{ Failure } & \multicolumn{2}{|c|}{$\begin{array}{c}\text { Total } \\
\text { probabilities }\end{array}$} & \multicolumn{2}{|c|}{ Optimized values } & \multicolumn{2}{|c|}{ Failure } & \multicolumn{2}{|c|}{$\begin{array}{c}\text { Total } \\
\text { probabilities }\end{array}$} \\
\hline $\mathrm{S}+\mathrm{T}+\mathrm{O}$ & 0.00073 & $S$ & 0.00073 & $\mathrm{~B}$ & $19.4 m$ & $\mathrm{~S}+\mathrm{T}+\mathrm{O}$ & 0.00056 & $S$ & 0.00056 \\
\hline $\mathrm{S}+\mathrm{T}$ & 0 & $\mathrm{~T}$ & 0.00168 & Cost & $38085.4 \$ / \mathrm{m}$ & $\mathrm{S}+\mathrm{T}$ & 0 & $\mathrm{~T}$ & 0.00098 \\
\hline $\mathrm{S}+\mathrm{O}$ & 0 & $\mathrm{O}$ & 0.00929 & & & $\mathrm{~S}+\mathrm{O}$ & 0 & $\mathrm{O}$ & 0.00929 \\
\hline $\mathrm{T}+\mathrm{O}$ & 0.00094 & & & & & $\mathrm{~T}+\mathrm{O}$ & 0.00042 & & \\
\hline $\mathrm{S}$ & 0 & & & & & $\mathrm{~S}$ & 0 & & \\
\hline$T$ & 0.00041 & & & & & $T$ & 0 & & \\
\hline $\mathrm{O}$ & 0.00832 & & & & & 0 & 0.00832 & & \\
\hline No failure & 0.98065 & & & & & No failure & 0.99071 & & \\
\hline
\end{tabular}

Analyzing Case 1, it is possible to conclude that any failure event occurring after fuse failure includes overtopping or, in other words, fuse failure is always combined with at least overtopping. Notice that this was the purpose of the fuse parapet design. When the fuse parapet is in place just overtopping is registered. This is due to the fact that the fuse parapet is designed to fail when sliding or overturning is likely to occur although fuse failure is not always enough to avoid sliding and/or overturning. For this particular study, overtopping and overturning are the most restrictive failure modes.

Case 2.1, that is, the optimized geometry of Case 1 but assuming a whole fixed parapet, does not satisfy the overturning probability constraint, as it was expected. In order to fulfill safety requirements, minimum caisson width has been calculated (Case 2.2), obtaining a value that is $6.6 \%$ wider and $6.5 \%$ more expensive than the one obtained in Case 1.

Thus, the effectiveness of the fuse parapet is confirmed for this particular case. Notice that this solution may not be applicable for every location and may have better results in certain places.
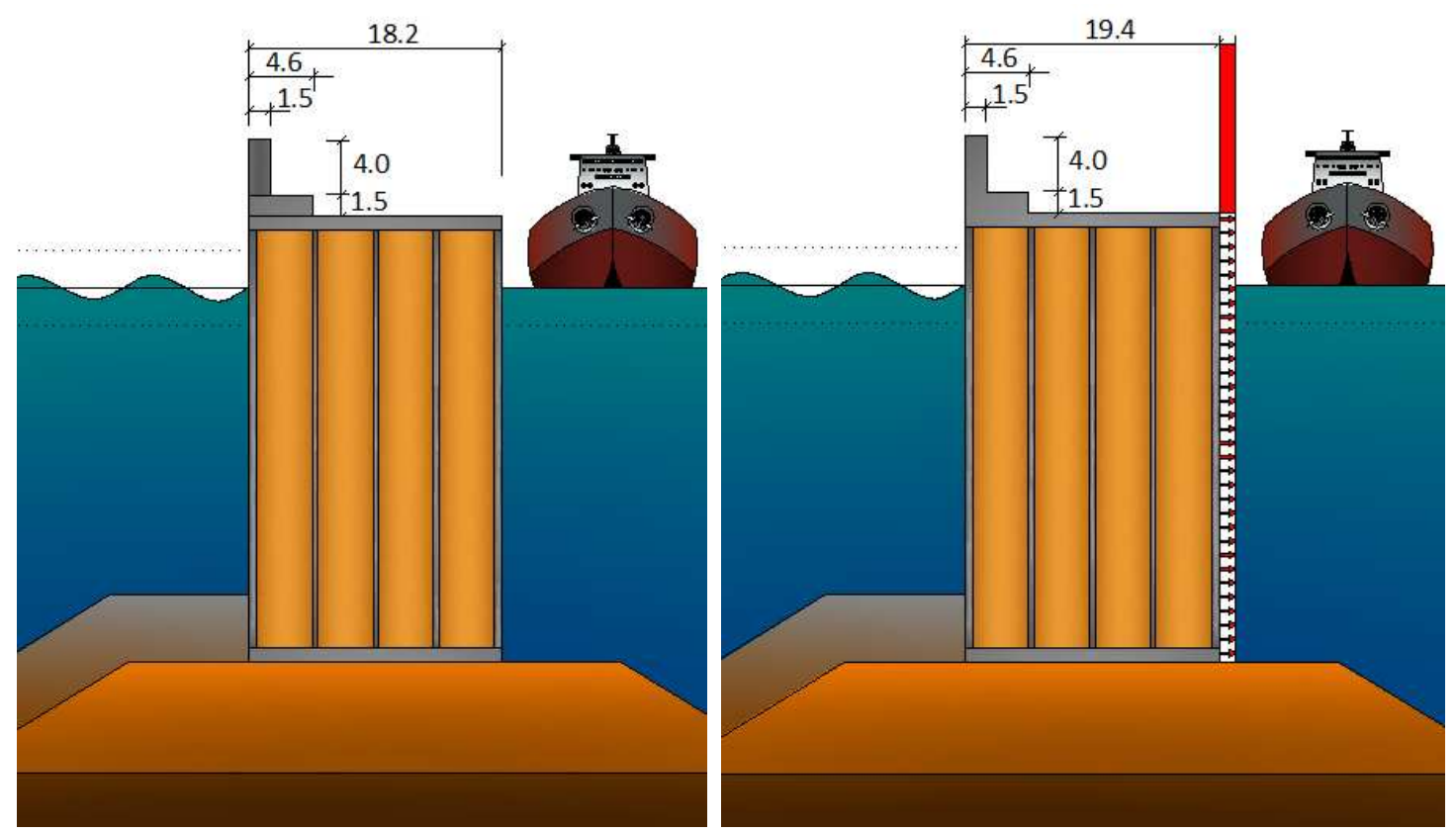

Figure 10. Optimized geometry of Case 1 (left) and Case 2.2 (right)

\section{CONCLUSIONS}

In the present paper it have been exposed how the combination of failure modes can modify the failure probability of the structure, increasing or reducing it. Despite physical interaction between failure modes is important, it is not yet well understood and, so, more research is needed.

A particular design proposal, the fuse parapet case, has been presented. This is not only an alternative way of facing breakwater design but also a practical example of how inducing failure of 
some elements of the structure can reduce its global risk and make it cheaper. Furthermore, the fuse element can help us deal with uncertainty related to tails in extreme values.

However, taking into account that the present paper is just a starting point, more research is needed on reparation and maintenance costs for the different cases studied and dynamic analysis of the fuse failure. Also new fuse failure criteria can be proposed and construction considerations, related to these criteria, can be defined.

\section{ACKNOWLEDGEMENTS}

The authors are indebted to the Spanish Ministry of Science and Innovation under project BIA2009-10483 and Puertos del Estado for partial support.

\section{REFERENCES}

Burcharth, H. F., 1997. Reliability-based design of coastal structures. Advances in Coastal and Ocean Engineering. Volume 3, pp. 145-214.

Castillo, E., 1988. Extreme Value Theory in Engineering. Academic Press, New York.

Castillo, E., Losada, M. A., Mínguez, R., Castillo, C., Baquerizo, A., 2004. Optimal engineering design method that combines safety factors and failure probabilities: application to rubble-mound breakwaters. Journal of waterway, port, coastal and ocean engineering. pp 77-88

Castillo, C., Mínguez, R., Castillo, E., Losada, M. A., 2006. An optimal engineering design method with failure rate constraints and sensivity analysis. Application to composite breakwaters. Coastal Engineering. 53 pp 1-25

EurOtop, 2007. Wave Overtopping of Sea Defences and Related Structures: Assessment Manual

Galambos, J., 1987. The Asymptotic Theory of Extreme Order Statistics. Robert E. Krieger Publishing Company, Malabar, Florida.

Gómez, R., Molina, R. y Castillo, C. 2009. Propuesta de metodología para verificación de fiabilidad de una estructura marítima mediante la aplicación de la probabilidad condicionada. Jornadas españolas de Ingeniería de Costas y Puertos (en prensa) (In Spanish)

Mínguez, R., Castillo, E., Castillo, C., Losada, M. A., 2006. Optimal cost design with sensitivity análisis using decomposition techniques. Application to composite breakwaters. Structural Safety 28. pp 321-340

PROVERBS, Probabilistic design tools for vertical breakwaters, 2005

Puertos del Estado. 2001. ROM 0.0, General procedure and requirements in the design of harbour and maritime structures. 